\title{
PÓS-MODERNIDADE, CAPITALISMO E CONHECIMENTO: UMA ANÁLISE CRÍTICA
}

\section{Luciana Gomes}

Daniel Martínez-Ávila

Marta Lígia Pomim Valentim

\begin{abstract}
Bacharela em Ciências Sociais. Mestranda em Ciência da Informação na Universidade Estadual Paulista (UNESP), Faculdade de Filosofia e Ciências, Marília. E-mail: luciana.gomes@unesp.br.
\end{abstract}

Possui Graduação em Biblioteconomía y Documentación pela Universidad Carlos III de Madrid (2005), Licenciado em Documentación pela Universidad Carlos III de Madrid (2007), Mestrado em Investigación en Documentación pela Universidad Carlos III de Madrid (2009) e Doutorado internacional pelo Programa Oficial de Doctorado en Documentación pela Universidad Carlos III de Madrid (2012). Professor Assistente da Universidade Estadual Paulista (UNESP/Marília). E-mail: dmartinezavila@marilia.unesp.br.

Professora Titular da Universidade Estadual Paulista (UNESP/Marília). Doutora em Ciências da Comunicação pela Universidade de São Paulo (USP), 2001. Mestre pela Pontifícia Universidade Católica de Campinas (PUC-Campinas), 1995. Bolsista Produtividade em Pesquisa (PQ) do Conselho Nacional de Desenvolvimento Científico e Tecnológico na área de inteligência organizacional, gestão da informação, gestão do conhecimento e cultura informacional. E-mail:valentim@valentim.pro.br.

\section{RESUMO}

O pensamento iluminista ao assumir à centralidade no desenvolvimento científico ocupado anteriormente pela religião buscou a razão em detrimento à fé apostando na Ciência toda sua racionalidade. Nesse contexto, ocorre o embate entre Modernidade e Capitalismo, que se apropriou de novas possibilidades de conhecimento gerado em uma nova perspectiva de Ciência, para legitimar sua relação com a natureza e com o homem. As críticas feitas à Modernidade e a discussão acerca de sua superação pela Pós-Modernidade revelam os problemas advindos do modo de produção e de suas novas configurações, a proposição de 
abandono o processo histórico e a liquidez das relações atendem aos anseios dessa nova dinâmica, os meios de comunicação trazem a necessidade permanente de novas informações com a fragmentação do tempo e uma série de presentes perpétuos (JAMESON 1984). Diante do desenvolvimento tecnológico a vida se torna vitrine exposta em redes sociais, o momento a ser vivido é o presente, em grande medida exposto pelas redes, gerando a fragmentação e a impossibilidade de projetos emancipatórios ou de reconhecimento de pertencimento do indivíduo. A promessa pós-moderna de desenvolvimento ilimitado e fim das fronteiras reforça a lógica individualistas e impossibilita o desenvolvimento de identidade enquanto sujeitos coletivos, negando ao homem a condição de sujeito histórico. No discurso pós-moderno, destacado por Boaventura (1999), por meio de três perplexidades, ocorre à desvalorização da economia em detrimento do político, social e cultural, no enfraquecimento dos Estados com a internacionalização da economia e o indivíduo como protagonista de mudanças. Neste trabalho, pretende-se analisar a relação entre a modernidade e a pós-modernidade e suas contribuiçõos e fracassos. Diante da perspectiva dialética busca-se compreender que as perspectivas deste novo paradigma são de grande valor e necessários ao debate, entretanto, as relações de trabalho e acumulação capitalista permanecem dominantes, bem como o consumo, mesmo diante do esgotamento de recursos naturais. A responsabilização individual tende a valorizar o discurso da meritocracia e a permanência do conceito de classes se torna essencial para a compreensão e o rompimento com as relações sociais e políticas vigentes.

PALAVRAS-CHAVE: Pós-Modernidade. Modernidade. Capitalismo. Conhecimento.

\title{
POSTMODERNITY, CAPITALISM AND KNOWLEDGE: A CRITICAL ANALYSIS
}

\begin{abstract}
When Enlightenment's thought assumed the main role in the development of knowledge, a role previously played by religion, it privileged reason over faith by putting all rationality on science. It is in this context in which the clash between Modernity and capitalism appears, as capitalism appropriated the new possibilities of knowledge produced by the new perspective of science in order to legitimize its relationship with nature and man. The critiques made to Modernity and the discussion about its overcoming by postmodernity reveal the problems caused by the mode of production and its new configurations, the proposed end of the historical approach, and the liquidity of the relations meeting the goals of this new dynamics, as media bring the permanent need for new information with the fragmentation of time and a series of perpetual gifts (JAMESON 1984). Due to the new technologies, life is exposed in social networks, focusing on the present moment that is exposed by in a fragmented way, precluding emancipatory projects and the association of individuals for instance by class. The postmodern promise of unlimited development and the end of frontiers reinforces the individualistic logic and precludes proposals for the development of identities as collective subjects while denying man the status of a historical subject. In the postmodern discourse, according to Boaventura (1999), there are
\end{abstract}


three perplexities: the devaluation of the economical dimension to the detriment of the political, social, and cultural aspects; the weakening of the states with the internationalization of the economy; and the individual as the protagonist of changes. In this context, we aim to analyze the relationships between modernity and postmodernity as well as its contributions and failures. Based on a dialectic perspective, we aim to find out if the perspectives of the new paradigm are indeed of great value and worthy of discussion, while indeed capitalist labor relations, accumulation of capital, and consumption remain dominant even at the doors of the depletion of natural resources. While individual accountability tends to value the discourse of meritocracy, the concept of classes becomes essential in understanding and breaking with the existing social and political relations.

KEYWORDS: Postmodernity. Modernity. Capitalism. Knowledge.

\section{INTRODUÇÃO}

A gestão, organização e mediação do conhecimento na era capitalista está condicionada pelos métodos e epistemologias da pós-modernidade, os quais sucederam a modernidade numa situação de progresso e superação do passado. Não obstante, a relação entre o capitalismo e pósmodernidade está marcada por uma série de contradições do próprio sistema capitalista que não tem sido resolvidas até hoje e permeiam a academia e seus métodos de análise. Pretende-se analisar a relação entre a modernidade e a pós-modernidade e suas contribuições e fracassos.

Diante da perspectiva dialética busca-se compreender que as perspectivas do novo paradigma são de grande valor e necessários ao debate, mas as relações de trabalho e acumulação capitalista permanecem dominantes bem como o consumo mesmo diante do esgotamento de recursos naturais. A responsabilização individual tende a valorizar o discurso da meritocracia e a permanência do conceito de classes torna-se essencial na compreensão e rompimento com as relações sociais e políticas vigentes.

\section{MODERNIDADE, FRACASSOS E CONTRIBUIÇÕES E A PÓS-MODERNIDADE}

A razão iluminista ao assumir a centralidade no desenvolvimento científico anteriormente ocupado pela fé religiosa busca separar fatos e valores na transformação da natureza que passa a ser dominada e reduzida a mero instrumento (PIERUCCI, 2011). Na medida em que são conquistados avanços científicos e tecnológicos, justifica-se a relação hierárquica que o homem passa a ter com a natureza em nome da continuidade do progresso científico. Tal processo histórico de desencantamento do mundo caracterizado por Weber já havia sido observado por Marx ao analisar a relação utilitária que o homem passa a exercer 
sobre a natureza quando passa a dominá-la e "subjugá-la às necessidades humanas, quer como objeto de consumo, quer como meio de produção" (1973, p. 40).

Sob a bandeira do progresso científico e da modernidade foram justificados ao longo da história genocídios por meio de discursos de eugenias e a destruição da natureza que foi colocada à disposição do homem possibilitando ignorar consequências éticas e até mesmo de sobrevivência desde que embasados por métodos racionais e quantificáveis. Na medida em que a ciência avançou surgiram questionamentos acerca de conquistas e retrocessos que a razão iluminista proporcionou, questionamentos quanto aos seus métodos foram respondidos com novas formas de interpretação e métodos, da investigação empírica de Francis Bacon ao método racional de René Descartes, com o positivismo de Augusto Comte à dialética marxista.

A busca por compreender a dinâmica social com as rápidas mudanças tecnológicas e científicas nas quais estamos inseridos trouxe à tona o questionamento quanto à superação do paradigma moderno e a defesa de um novo paradigma emergente, que buscaria responder as novas relações sociais defendidas pela pós-modernidade. Para compreender esse embate, o contexto social, político e histórico, não pode ser ignorado, bem como as relações econômicas e o modo de produção e consumo.

O sociólogo Boaventura de Souza Santos afirma que estamos encerrando um ciclo de determinada ordem científica (1988, p.47). Para o autor, defensor da pós-modernidade, a modernidade cumpriu seu papel e torna-se um modelo totalitário. A modernidade já foi criticada pelos alemães Theodor Adorno e Max Horkheimer, da denominada escola de Frankfurt, quando questionada devido ao excesso de razão, de luz, contrapondo com o que se chamou de idade das trevas o período histórico anterior dominado pelo clero, apontando que o excesso de razão, na obra Dialética do Esclarecimento, cegou a humanidade, sem negar o estado de barbárie no qual a sociedade está mergulhada, mas apontando a necessidade de submeter à razão a um processo dialético. Não há rompimento com o paradigma moderno e com sua base teórica marxista e materialista histórica.

Sem o uso da razão dialética, para os autores frankfurtianos, a desconstrução da barbárie e os pressupostos iluministas de liberdade, fraternidade e igualdade não são possíveis. Nesse sentido, o capitalismo se apropria da fé inquestionável da razão, reivindicando-a. As superstições, pensamento mágico e religiões perdem parte de sua influência. A crença inquestionável na razão faz com que os autores questionem a instrumentalização dos sentidos, o embrutecimento da humanidade, mas sem deixar de apontar o capitalismo e suas contradições. 
Diante da percepção de excesso de razão, procura-se retomá-la, sem seus excessos.

Por meio de outra abordagem historicista, Helen Meiksins Wood defende o paradigma moderno apontando que a crítica que os teóricos pós-modernos fazem deveria ser contra a razão capitalista, e não contra a racionalidade moderna. Considerando tal aspecto, evidencia-se como forma ideológica à crítica como um todo e não especificamente ao capitalismo. A fluidez proposta pela pós-modernidade impossibilita a construção de projetos universais e reconhecimento de indivíduos como classes, o homem deixa de ser sujeito histórico, a natureza do eu humano é fragmentada, impossibilitando o desenvolvimento de identidade (WOOD, 1996 p. 123). Com a não identidade enquanto sujeitos a perspectiva de organização e mobilização deixa de ser expressiva.

O discurso pós-moderno ao buscar o fim das fronteiras e o consequente relativismo resultante explica, em certa medida, a apatia política diante da retirada dos direitos dos trabalhadores brasileiros com a recente reforma trabalhista. O não reconhecimento enquanto classe trabalhadora não possibilita a concepção de sujeito histórico capaz de realizar transformações sociais. A relação entre a política e interesses de classes é ofuscada pela não percepção do local ao qual se pertence. Ocorre excessiva dispersão e fragmentação, a classe trabalhadora para a pós-modernidade deixa de existir e como reflexos há identidade local é abandonada.

O trabalhador perde sua identidade enquanto classe e suas horas de lazer passam a ser apropriadas pela lógica do capitalismo. Com a mercantilização do trabalho o tempo livre do trabalhador também é mercantilizado e a ele é oferecida apenas uma cultura de massas, pois o tempo de descanso também foi apropriado pelo capital. Para Adorno (2002, p.113) podem desfrutar de tempo livre com qualidade indivíduos emancipados, não seres heterônomos se si mesmos. A visão de totalidade está presente assim como a perspectiva da significação do papel que a economia concentrada exerce nas relações com a cultura que se transforma em mero entretenimento naturalizando a lógica do lucro em mais uma indústria capitalista.

Nos países de maior desenvolvimento capitalista a indústria cultural, não coincidentemente, também se desenvolveu de forma bastante expressiva e utilizando-se do cinema para reforçar o discurso de um modo de vida de sucesso. Há uma relação íntima entre a o desenvolvimento capitalista e o avanço da indústria cultural, exatamente por ser necessário ao desenvolvimento do sistema de dominação maior controle sobre a autonomia do indivíduo.

A indústria cultural não permite experimentar e por isso a todo o momento se fala do 
novo, quando há sempre algo familiar no pretenso novo. A arte tornou-se apenas elemento de diversão, entretenimento. Os produtos culturais, com declínio da aristocracia no século XIX, são inseridos na nova lógica de competição do mercado (HARVEY, 1992, p.31). Na lógica pósmoderna há o enfraquecimento da crítica e das contradições. Há décadas de ideologias legitimando a atual ordem, em diferentes áreas do conhecimento e da experiência.

Sem romper com a modernidade e com o pensamento racional, Adorno afirma que "É preciso mais razão, e não menos, para curar as feridas que a ferramenta razão, em um todo irracional, infligiu à humanidade" (2003, p. 159).

O capitalismo se apropriou da modernidade e se utilizou de suas conquistas científicas para legitimar seu modo de exploração, o trabalhador suporta não somente a alienação, mas também adere ao discurso da pós-modernidade como responsável exclusivo por sua condição, em seu discurso individualista e democrático proporciona bases para a manutenção do mesmo modo de produção.

O discurso de democracia, acesso e possibilidades trazidos pela pós-modernidade e a crença de abarcar a todos os discursos, relativizar, presença de autobiografias, e de uma ciência autorreferente, embora pareça agregar, pode respaldar discursos de responsabilização individual, descontextualizando suas origens e não considerando as reais possibilidades impostas diante de desigualdades sociais.

A separação entre a política e a economia, reduzindo as contradições e retirando a lutas de classes, separação de detentores dos meios de produção e vendedores de força de trabalho, por apenas "polarização binária" (GUERRA SOBRINHO, 1997, p.109), possibilita reforçar o discurso hegemônico de sociedade democrática, quando, por vezes, ela existe de forma distorcida.

O discurso pós-moderno impossibilita projetos emancipatórios e se perde a noção de processos. O capitalismo é visto como a mais racional experiência que se impôs deixando para o individuo a responsabilidade pelo seu fracasso.

A liberdade pessoal na perspectiva marxista só é possível em comunidade, sem a qual o desenvolvimento não pode acontecer (ANDERSON, 1999, p. 121). Só existe desenvolvimento em conexão com o outro, no coletivo. A promessa de desenvolvimento ilimitado e sem controle pós-moderna apenas reforça a ideologia individualista capitalista.

\section{PERPLEXIDADES PÓS-MODERNAS E INTERDISCIPLINARIEDADES}


Para Boaventura (1999, p.20) a modernidade já cumpriu seu papel com excessos e déficits, ela deixa de possuir a energia vital, sindicatos, partidos e organizações não existem mais e por meios de uma proposta esquematizada se propõe a pensar em perplexidades, isto é, pensar novas formas a partir das "ruinas da modernidade". Para ocorrerem mudanças drásticas, ele aponta os novos conhecimentos que se fazem necessários. As perplexidades apontadas por Boaventura (1999, p.21) consistem na desvalorização da economia em detrimento do político, social e cultural.

Um contraponto se faz necessário nessa indicação, a economia e suas relações ainda são a base das relações capitalistas, não é possível determinar o cultural, social e político diante da grande concentração de capital e atendimento exclusivos aos seus interesses. Tal relação impossibilita a implantação de políticas sociais abrangentes de forma eficiente. Mesmo diante da desmaterialização do sistema monetário, e as grandes transformações decorrentes dela, a lógica acumulativa permanece.

Uma segunda perplexidade apontada é a internacionalização da economia com novas práticas transnacionais e a translocalização de pessoas e descentralização dos Estados.

Apesar do enfraquecimento os Estados ainda buscam se fortalecer mesmo diante de um discurso de ódio e resistência aos imigrantes, com o discurso de pertencimento local, grupos neonazistas aparecem fortalecidos e discussões que pareciam dormentes renascem. Existe uma contradição nesse aspecto, turistas são bem vindos e tem sua segurança garantida, enquanto imigrantes são deportados ou perdem suas vidas a tentar adentrar em outro país ilegalmente. A diferença está justamente nas relações econômicas e consequências financeiras entre aceitar um e outro. Ora, a translocalização de pessoas se dá no âmbito financeiro, no poder monetário para o acesso ao deslocamento, são mercadorias que não possuem fronteiras, o capital financeiro, e não as pessoas.

A terceira perplexidade aponta o individuo como protagonista de mudanças, microhistória, biografias. Mas o resultado são indivíduos vigiados e solitários, apáticos e protegidos frente à internet. Há o fortalecimento de posturas fascistas diante da possibilidade de anonimato proporcionada ao se posicionar em redes sociais. Ocorrem julgamentos morais sem a menor demonstração de empatia.

Nesse processo de transição paradigmática ocorre também o esgotamento dos recursos naturais e por outro lado emerge o discurso ecológico. Mas o progresso não deixa de ser convertido em acumulação, ocorre a transformação da natureza em mero meio de produção. A 
venda de cotas de carbono por parte de países que não possuem expressiva industrialização a países que extrapolam sua cota devido ao alto nível de poluição torna-se emblemática. Nesse sentido as leis incentivam a continuidade da poluição, mesmo diante do consenso que o planeta está se esgotando e não é possível manter o mesmo nível de consumo.

Segundo mostra Victor Lebow em "Ending the Depression of Retailing” (1955 apud PACKARD, 1960, p.24), o cerne da questão não é questionado, o consumo permanece incentivado, a lógica baseia-se em transformar o consumo em modo de vida e o ato de comprar se transforma em ritual, por meio da satisfação do ego pelo consumo, as coisas devem ser consumidas e descartadas de forma rápida.

No discurso pós-moderno a ecologia emerge como preocupação global e a necessidade de alterar a relação com o meio é colocada como ponto fundamental, discute-se não mais instrumentalizar a natureza, mas com uma nova proposta, por meio da busca do entendimento da ecologia de forma interdisciplinar. Dentro da perspectiva pós-moderna a ecologia é um ponto aglutinador que pertence às ciências sociais, naturais e à cultura e que deve ser analisada sob os diferentes aspectos.

A Teoria Geral dos Sistemas (TGS), criada pelo biólogo e filosofo Ludwig Von Bertalanffy, passa a ser aplicada a fim de compreender áreas científicas diferentes. Para Morin (2005, p.20), a TGS situa-se em nível transdisciplinar, rompendo a concepção clássica que pode ser estendido também a outras áreas do conhecimento. Tal teoria defende a análise visando compreender o sistema como um todo, apesar das partes que o compõe. Qualquer desequilíbrio em uma das partes acarretará em desequilíbrio no todo, mas o desequilíbrio permite que o sistema mantenha-se em equilíbrio (MORIN, 2002, p. 22).

A Teoria Geral dos Sistemas permitiu buscar uma análise mais ampla e questionou a divisão do conhecimento em disciplinas.

A organização disciplinar foi instituída no século XIX, notadamente com a formação das universidades modernas; desenvolveu-se, depois, no século $\mathrm{XX}$, com o impulso dado à pesquisa científica; isto significa que as disciplinas têm uma história: nascimento, institucionalização, evolução, esgotamento, etc.; essa história está inscrita na da Universidade, que, por sua vez, está inscrita na história da sociedade (MORIN, 2002, p. 105). A perspectiva disciplinar, científica e o modelo educacional vigente, dificultam um conhecimento interdisciplinar. As possibilidades são reduzidas ao esforço individual do pesquisador ou docente para compreensão da realidade sob tal ótica. 


\section{CONSIDERAÇÕES FINAIS}

Conclui-se que a tentativa de compreender a realidade social por meio da pósmodernidade é falha. Não se rompeu com o modo de produção capitalista. O paradigma da pósmoderna trouxe aspectos que não podem ser desconsiderados e de grande importância ao valorizar o indivíduo e possibilitar voz a minorias, homossexuais, mulheres, negros passam a conquistar espaço social, mas ainda são por vezes apenas potencialmente consumidores para nichos capitalistas.

A crise da modernidade para qual Boaventura aponta é compreensível na medida em a modernidade foi associada ao capitalismo e com ele mantém íntima relação, desde seu surgimento com a busca de consolidação de influências da burguesia em detrimento do poder da nobreza a qual se colocava como entrave ao enriquecimento e acúmulo de riquezas e disputava seu poder. A industrialização da ciência trouxe como consequência coloca-la a disposição dos centros de poder econômico, social e politico, que passaram a definir as pesquisas e prioridades científicas. (BOAVENTURA, 1999, p.59). Nesse sentido, o capitalismo permanece central.

A crise é do capitalismo, diante da dificuldade de consumir os excedentes, trata-se de uma crise sobre acumulação e tentativa de manutenção de poder, não da modernidade (MUSSE). O capital permanece acumulado e o trabalho mantém sua centralidade, de forma cada vez mais precarizada. A luta de classes permanece como alternativa a qualquer saída individual.

\section{REFERÊNCIAS BIBLIOGRÁFICAS}

ADORNO, Theodor W; HORKHEIMER, Max. Dialética do Esclarecimento. Tradução de Guido Antônio de Almeida, Rio de Janeiro: Zahar Editores, 2002.

ADORNO, Theodor W. O ensaio como forma. In: Notas de literatura. Trad. Jorge de Almeida. São Paulo: Zahar Editores. 2003

ANDERSON, P. As Origens da PósModernidade. Rio de Janeiro, Zahar Editores, 1999.

GUERRA SOBRINHO, 1. D. O PósModernismo e as Ciências Sociais: anotações sobre o atual estado da discussão. Impulso, Piracicaba, n.29, p.99-112, 1997.

MARX, Karl. Grundrisse. São Paulo: Boitempo, 2011.

MORIN, Edgar. A cabeça bem feita. Repensar a reforma repensar o pensamento. 6 ed., Rio de janeiro: Bertrand Brasil ltda, 2002.

MUSSE, Ricardo. Z Cultural. Disponível em: http://revistazcultural.pacc.ufrj.br/odeba te-marxista-sobre-a-pos-modernidadede-ricardo-musse/ Acesso em 30/08/2017. 
PACKARD, Vance. The Waste Makers. New York, David Macay, 1960.

PIERUCCI, Antônio Flávio. $O$ desencantamento do mundo: todos os passos do conceito em Max Weber. São Paulo: Editora 34, 2011.

SANTOS, B. de S. Pela mão de Alice: $o$ social e o político na pósmodernidade. 7.ed. Porto: Edições Afrontamento, 1999.

SANTOS, B. De S. Um discurso sobre as ciências na transição para uma ciência pósmoderna. Estudos Avançados, vol.2, no.2, São Paulo, May/Aug. 1988 Disponível em: http://www.scielo.br/scielo.php?script= sci_arttext\&pid=S0103-

40141988000200007 <Acesso em 29/08/2017> Acesso em 30/08/2017.

WOOD, Ellen Meiksins. Em defesa da História: o marxismo e a agenda pósmoderna. Crítica Marxista, São Paulo, v.1, n.3, 1996, p.118-127.

GOMEZ, L.; MARTINES-ÁVILA, D.; VALENTIM, M. L. P. Pós-Modernidade, Capitalismo e Conhecimento: Uma Análise Crítica. Complexitas - Rev. Fil. Tem. Belém, v. 3, n. 1, p. 120-129, jan./jun. 2018.

Disponível em: http://www.periodicos.ufpa.br/index.php/complexitas/article/view/6637 Acesso em: 20 de fevereiro de 2019. 